\title{
LIVING WITH NEGATIVE ATTITUDES TOWARDS THE STUDY OF L1 IN GHANAIAN SENIOR HIGH SCHOOLS (SHS)
}

\author{
Charles Owu-Ewie and Dora F. Edu-Buandoh
}

Some languages ... achieved greatness naturally partly by sheer force of numbers... Some others achieved greatness through sociohistorical forces being in their favour... still others have simply had greatness thrust upon them by decrees (Adegbija 1994)

\begin{abstract}
The study and use of indigenous African languages in education have been viewed unfavourably by many, including African scholars. This has resulted in fewer educated Africans studying their indigenous languages in school. Africans who study their languages in school beyond Junior High School are seen as "academically weak". Sometimes, a student's poor performance in English and other subjects is attributed to his/her constant use of the indigenous language (Andoh-Kumi1997). In 1994, the study of Ghanaian languages as a core subject in the Senior High School (SHS) was abolished because it was erroneously conceived as a contributing factor to the abysmal performance of students in English, in particular, and other academic subjects, in general. Since then, the study of a Ghanaian language at the Senior High School has suffered a serious setback culminating in considerably reduced enrolment of students who study Ghanaian languages. Students offered a Ghanaian language as part of their SHS programs accept it reluctantly. It is therefore important to investigate this phenomenon in the SHS. This qualitative study used semi-structured interviews and observations as data collection strategies to investigate the negative attitude of Ghanaians towards the study of L1 in the SHS, and how SHS students studying their L1 are coping with the negative attitude. The study also examines ways that the negative attitude towards the study of L1 in SHS can be changed.
\end{abstract}

http://dx.doi.org/10.4314/gjl.v3i2.1 


\section{Introduction}

Language attitudes cannot be ignored when talking about language planning and language policy formulation. Language attitudes play a central role in determining levels of success for the learning and acquisition of a second language. The significance or role of attitude in language education, planning and development has been clearly expounded by researchers in Africa and elsewhere in the world (Mparutsa, Thondhlana \& Crawhall, 1990). It is therefore crucial for language policy makers and planners to take into consideration people's language attitudes and preferences so that the policies can reflect the needs of the people and not the interest of any particular language (Webb 1996). In places like Ghana, where the attitudes of the people have been taken for granted and ignored, the policy of using the child's L1 as medium of instruction at the lower primary school and English after primary three, which is professed to have enhanced academic performance has not yielded the desired result.

Ghana is a multilingual society. The precise number of indigenous languages that exist within the borders of Ghana is however, a subject which has not been conclusively agreed upon by linguists. The least number proffered is forty, while the largest estimate is eighty-three (Owu-Ewie 2009). In addition to these languages, English is the official language of the country. The geographical location of Ghana, bordered by French-speaking countries, has made French relevant to the Ghanaian school curriculum. One striking feature, however, of the language situation in Ghana is the widespread use of English which is endangering the indigenous languages and has resulted in the narrowing of the domains within which the local languages are used (Guerini 2008). English is used in wider and more prestigious situations than the indigenous languages. The prestigious and functional status that English has acquired has also resulted in the Ghanaian populace developing positive attitudes towards its use and study in schools, while the local languages have been accorded an unfavourable negative attitude.

Language attitude plays an important role in language choice and policy in multilingual societies (Wamalwa 2013). According to Wamalwa, people who reside in a monolingual society have only one attitude towards their language because they have no other languages to compare with theirs. On the contrary, in situations where speakers are bilingual or multilingual, there is the inclination to develop different attitudes to each of the languages used. Attitude, whether positive or negative, depends on the degree of socio-economic value attached to each language (Omoniyi 
2014). A multilingual country like Ghana, which runs a bilingual policy in education, is therefore a fertile ground for language attitude manifestation. English is the official language of Ghana and highly preferred in education. English is used to determine the academic progression of a student. That is, progression from the Senior High School to the tertiary level and indeed to all other higher levels of education is determined by a credit pass in English. In education, "English has been assigned a higher prestige and is perceived as the only language worth being literate in or even the sole language worth investing ... to the detriment of local languages and vernaculars" (Guerini 2008: 2). As a result of what pertains in education in terms of language use, the study of Ghanaian language is often not favoured. The common prejudice depicts Ghanaian languages as unfit for use in formal, institutional and official domains. In the educational system in Ghana, teachers, lecturers and even professors teaching indigenous languages are looked down upon by their peers who may classify them as 'second-rate' colleagues; an attitude that inevitably affects students (Guerini 2008). This view is so deeply rooted in the mind-set of some parents that they are disappointed when they learn that their children are learning their own languages at school, especially in the Senior High School or the University (Andoh-Kumi 1997). In Nigeria, Bamgbose (1991) has also noted that teachers of indigenous languages are not much sought for, and quite often, students do not consider them as academically proficient.

Students who study a Ghanaian language as part of their program of study tend to be dismissed as under-achievers who turn to easier options to attain good results. This perception comes from the belief that Ghanaian languages are not valued subjects to be studied. One is supposed to learn one's own language at home and not in school. The misconception among Ghanaians in relation to the study of Ghanaian languages is that they perceive Ghanaian language study as just learning to speak the language. It must be noted that language learning goes beyond speaking. There are so many Ghanaians who can speak their native language but cannot write in it or discuss academic matters in the language. It should be recognised that attitude plays a key role for one to be a successful language learner. It is therefore crucial to investigate how SHS students are living with these negative attitudes towards learning a Ghanaian language and also, to examine ways that these negative attitudes can be reversed. Though there have been few studies on language attitudes in Ghana (Amissah, et. al. 2001; Kwofie 2001; Edu-Buandoh 2010; Sarfo 2013), not much attention has been paid to the study of language attitudes in Senior High School students studying Ghanaian language. This paper explores this terrain to bring the issues to the fore. 


\section{Literature Review}

This section of the study looks at the study and use of Ghanaian languages in education, language attitudes, and attitudes towards language in education.

\section{L1 Study in the Ghanaian Educational System}

Presently, Ghana has a 2-9-3-4 educational structure. There is a 2-year kindergarten (KG 1 and 2) and a basic education system made up of six years primary education and three years Junior High School (JHS) education. This is followed by three years of Senior High School education and four years University (tertiary) education. In the Ghanaian educational system, two languages (English and a Ghanaian language) are used. This implies that Ghana practices bilingual education; an early-exit transitional type of bilingual education. It is the type which begins with a Ghanaian language as medium of instruction and later English language. To ensure that order prevails in the use of language in its schools, Ghana has an explicit language policy that governs the use and study of the two languages involved. The language policy of education in Ghana indicates that indigenous language (L1) should be used as medium of instruction from KG1 to Primary three, while English is studied as a subject from P1 to P3. There is a transition from L1 use as medium of instruction to English from primary four to the tertiary level. The study of a Ghanaian language is compulsory from Primary one to the end of the Junior High School program. The Ghanaian language is an examinable subject and counts towards certification at this level. Ghanaian language study used to be a core subject until 1994, when the Senior Secondary School (now Senior High School) concept was initiated.

Currently, Ghanaian language study is an elective subject for a few students in the SHS. In the Colleges of Education, Ghanaian language study is a core subject in the first year. It then becomes an elective in the second year for only a few students. At the tertiary level, there is a Department of Ghanaian Languages at the University of Education, Winneba, but at the University of Ghana and the University of Cape Coast Ghanaian Languages and Linguistics are combined into a single department. Kwame Nkrumah University of Science and Technology, Kumasi has Ghanaian language studies as part of the Modern Languages Department. These universities offer Bachelor of Arts (BA) or Bachelor of Education (BEd), Master of Arts (MA) and Master of Philosophy (MPhil) programs in a Ghanaian language. University of Education, Winneba offers the BA in Fante, Nzema, Twi, Ga, Dangme, Gonja, Kasem, Dagbani, Gurene, Dagaare, Ewe and recently Sisala. It also offers MPhil and MA programs in Akan (Fante and Twi), Ewe and MA/MPhil in Ghanaian Language Studies (for Ga, Dangme, Nzema, Gonja, Kasem, Dagbani, Gurene, and Dagaare). 
The University of Cape Coast offers BA, MA and MPhil in Akan (Fante and Twi) as well as in Ewe and Ga. KNUST offers only an undergraduate course in Akan, while University of Ghana offers BA and MPhil in Ga, Akan and Ewe. It could be seen that even the Universities that offer some degree programmes in Ghanaian languages target only few languages, considering that there are over forty Ghanaian languages.

\section{Language Attitudes}

The concept 'attitude' has been defined from different perspectives resulting in semantic disagreement and differences about the generality and specificity of the term (McKenzie 2010, cited in Wamalwa 2013, Bartram 2010). According to Bartram (2010), "attitude is a mental and neural state of readiness, organized through experience, exerting a directive or dynamic influence upon the individual's response towards all subjects and situations with which it is related". This is a mentalist perspective on the definition of attitude. From a behaviourist perspective, Fishbein \& Ajzen $(1975 ; 2000)$ see attitude as a learned predisposition to respond in a consistently favourable or unfavourable manner with respect to a given object. This definition implies that attitude is learned through a socialization process. Wamalwa (2013) is of the opinion that attitudes are not fixed but are constantly fluctuating and shifting according to the social environment. In another study, Gok and Silay (2010) note that attitude is a mental concept that depicts favourable or unfavourable feeling toward an object. According to the behaviourist and mentalist approaches to studying attitude, individuals are not born with attitudes, but attitudes are learned over the period of socialization; though Bohner and Wanke (2002) say attitudes may be inherited. Fasold (1984) also holds the view that an attitude is individual, but it has origins in collective behaviour.

Attitudes, according to the social psychologists, have three main components: cognitive, affective and conative/behavioural (Edwards 1994; Baker1992; Smit 1996). The cognitive component of attitude refers to a set of beliefs about an object, affective attitude includes feelings about an object, while conative/behavioural attitude is about the way people act towards an object (Salta \&Tzougraki 2004). Attitude can be expressed towards any object where comparison with another is involved. For example, attitude can be expressed towards the use of Ghanaian language as medium of instruction against the use of English as medium of instruction and attitudes towards transitional bilingual education against monolingual education. Thus, attitude is a psychological tendency that is expressed by evaluating a particular entity with some degree of favour or disfavour (Eagly \& Chaiken 1998). From the various definitions cited, it is opportune to identify with (Massey1986) that: 
a. Attitudes are selectively acquired and integrated through learning and experience;

b. Attitudes are enduring dispositions indicating response consistency;

c. Attitudes can be positive or negative in their effects on a social or psychological object

Some studies in language attitude have been strictly concentrated on language itself, but most often, the concept 'language attitudes' includes attitudes towards speakers of a particular language (Fasold 1984). The definition of language attitude is as varied as the concept of attitude itself, but there have been acceptable definitions put forward by scholars of the subject. Language attitude has been defined as the strong "positive or negative emotions experienced by people when they are faced with a choice between languages in a variety of situations or are learning a language" (Dyers 1998). Crystal (1997: 215) defines language attitude as the "feelings people have about their own language or the language of others". These two definitions do not cover other aspects of language attitude. An earlier look by Saville-Troike (1989: 181), from an ethnographic perspective explores language attitude by concentrating on interesting areas like "questions of how culture-specific criteria for 'speaking well' function in the definition of marking social roles, how attitudes towards different languages and varieties of language reflect perceptions of people in the different social categories, and how such perceptions influence interaction within and across the boundaries of a speech community...". Perhaps Richards et. al. (1992) catered for the missing elements in the first two definitions when they defined language attitude as attitudes which speakers of different languages or language varieties have towards each other's languages or to their own language. According to them, expressions of positive or negative feelings towards a language may reflect impressions of linguistic difficulty or simplicity, ease or difficulty of learning, degree of importance, elegance, and social status. The authors further state that language attitude studies could be categorised thus: (a) those that explore general attitudes toward language and language skills (b) those that explore stereotyped impressions toward language, their speakers, and their functions and (c) those that focus on applied concerns (language choice and usage, and language learning). Fasold (1987) acknowledges the deficiency in language attitude studies and recommends that language attitude can be broadened to encompass attitudes towards speakers of a particular language or dialect and attitudes toward language maintenance and planning efforts. Coronel-Molina (2009) citing Cooper and Fishman (1974) proposed two approaches that are essential to defining the concept. The first approach is concerned with defining language attitude in terms of the referent, thus looking at attitudes as towards language, language varieties, 
language variants and language behaviour. The second approach is to define language attitudes in terms of their effects or consequences. Language attitudes of this kind are those which influence language behaviour and behaviour towards language. CoronelMolina (2009: 9) in bringing the pieces together looked at key elements in the various perspectives in defining language attitude and concluded that attitude involves both beliefs and feelings, that it theoretically should influence behaviour, and that there are a range of issues about which people have language attitudes, from opinions about one's own language, to foreign speakers of one's own language, to foreign languages to official policies regarding languages. In this study, the definition by Crystal (1997: 215) that language attitude refers to the "feelings people have about their own language or the language of others" will be used as the working model, for it fits the study since the study sought to find out language attitudes towards the study and use of Ghanaian language in Senior High Schools, drawing the data from Ghanaian students and teachers.

\section{Attitudes to Language in Education}

The importance of language attitudes for language-in-education policies has been stressed by several researchers, like Edwards (1994), Heugh (2000), Andoh-Kumi et al. (2001) and Sarfo (2012). There is close relationship between language attitude and education because education is generally deemed to play a crucial role in shaping language attitudes and influencing the outcomes of language maintenance and language shift processes (Baker 1992), especially for countries which have no language policy, but use that of education as the national language policy. Adegbija (1994) points out that it is in education that the negative attitudes toward indigenous African languages are most glaringly displayed. This is so because most African countries do not have explicit language policies outside education. In most African post-Junior High schools, English is highly favoured. In Ghana, English which is a colonial language used in formal education is perceived as the only language worth being literate in or even the sole language worth investing in, to the detriment of local languages. In a multilingual situation like Ghana, language attitude in education is very essential. Learners' attitudes to language are integral part of learning and that it should be an essential component of second language learning pedagogy (Saracaloglu 2010) because language attitudes have effects on second language and foreign language learning. Siti (2008) found out that students' attitude towards a target language and its speakers correlates with their proficiency level in the language. The implication is that if students have positive attitude towards a language, they perform well in it. The effectiveness of language policies in education is determined more by the attitudes of the people towards language use than the simple demographic facts of 
language distribution and use (Ferguson 1996). Though finding data about language attitude is more cumbersome than finding the basic statistics of users of a language or language distribution, it is paramount for researchers to engage in this venture. It is possible that such a venture may raise political issues which threaten the successful implementation of a language survey, but as echoed by Webb (1996), it is very important for language policy makers and planners to consider people's language attitudes and preferences so that their policies can reflect the needs of the people and not the interest of any particular language. Lewis (1981:262) had earlier summed this up by saying that:

no policy will succeed which does not do one of three things: conform to the expressed attitudes of those involved, persuade those who express negative attitudes about the rightness of the policy, or seek to remove the causes of the disagreement.

There have been few studies of language attitude towards language use and study in Ghana, especially in education. These studies have always shown that there is negative attitude towards the use of indigenous language in education as medium of instruction and subject of study. A study conducted by Kwofie (2001) to compare University of Cape Coast students' attitudes towards English, Pidgin and Ghanaian languages found that participants have positive attitudes towards English and unfavourable (negative) attitudes towards Ghanaian languages. The findings of this study make the present study relevant because it adds to finding a solution to the larger puzzle of language attitudes towards studying or using Ghanaian languages in the Ghanaian educational system. In a study about The Implementation of Ghana's School Language Policy initiated by Improved Education Quality (IEQ) in collaboration with American Institutes for Research, University of Pittsburgh, Amissah et al. (2001) found that parents and teachers have positive attitudes towards the use of English as medium of instruction in schools and negative attitudes towards the use of Ghanaian language as medium of instruction. The study also found that pupils prefer their teachers to use English to teach so that they will be fluent in English, though they understood courses taught in Ghanaian language better than when these courses were taught in English. In the same study, some language teachers who taught languages other than Ghanaian languages had positive attitudes towards the use of English rather than towards the Ghanaian languages. They were of the opinion that the use of Ghanaian language as medium of instruction impedes progress in English and that the use of Ghanaian language as medium of instruction retards academic excellence. This particular study was conducted in six primary schools and six Teacher Training Colleges (now Colleges of Education). The present 
study is important because it provides information useful in language teaching and learning, and makes the study of language attitude in Ghana from the basic level to the tertiary level partially complete, since the study of language attitudes in the SHS has been left out in the discourse. The purpose of this study is to find out people's attitudes towards the study of L1 in the SHS in Ghana, examine how SHS students studying Ghanaian languages cope with negative attitudes towards the study of these languages, and suggest innovative ways of changing the negative attitudes of Ghanaians to the study of Ghanaian language at the SHS level.

\section{Methodology}

This study has a qualitative design. The study comprised eleven Senior High Schools purposively selected from both the Central and Western Regions of Ghana. The schools were selected for proximity, and also because they offer a Ghanaian language as elective subject. The eleven (11) SHSs comprised five (5) from the Western Region and six (6) from the Central Region. The schools used in the study are made up of two (2) girls' and nine (9) co-ed schools. Seven of the schools are in the 'B Category' (less endowed schools in terms of educational resources) and four in the 'A category' (well-endowed schools in terms of educational resources). The sample size used in the study consisted of eleven (11) teachers and one hundred and ten (110) students. The teachers and students were also purposively selected because they teach and study Ghanaian language respectively. The teachers comprised seven (7) females and four (4) males while the students were made up of seventy (70) females and forty (40) males because the female students were eager and voluntarily wanted to talk about the issue. Observations and interviews were the main tools used to collect the data. The complete observation type was employed by the researchers to observe the school environment in order to identify what facilitates or impedes Ghanaian language learning in each school. The researchers also observed students in the Ghanaian language classroom to examine their attitude towards Ghanaian language studies as opposed to the study of other academic subjects. In addition to the observations, semistructured interviews were used for the teachers and students. The students were interviewed in focus groups of 10 students each. The five teachers in the Western Region were interviewed together, the two teachers in the Cape Coast Municipality were interviewed together and the last four (outside the municipality) were also interviewed together. The focus group was used to save time and also to ensure confirmation of issues raised by others. With consent from participants, the interviews were audio recorded. The data analysis strategy used was the inductive analysis and creative synthesis approach. The responses from participants were put into categories based on the similarity of the responses. The data was also coded thematically based 
on emerging themes to describe the unfolding phenomenon. The data was presented using the narrative-logic approach in order for the analysis to be done transitioning from one exemplar to another and using excerpts from the data effectively in the presentation.

This research is guided by three key research questions:

1. What are people's negative attitudes towards the study of Ghanaian Language in Senior High Schools in Ghana?

2. How are students studying L1 in the SHS coping with the negative attitudes of people towards the study of L1?

3. How can the negative attitudes of people towards the study of L1 in SHS be changed?

\section{Findings and Discussion}

This section of the study answers the main research questions posed above.

What are people's negative attitudes towards the study of Ghanaian Language in Senior High Schools in Ghana?

This research question sought to find out from respondents the negative attitudes of non-teachers of Ghanaian language, non-Ghanaian language students, school administrators and parents towards the study of Ghanaian language in the SHS. Responses from participants generally indicated that there is negative attitude towards the study of Ghanaian language in the SHS. The following statements from participants (Ghanaian language teachers and students) interviewed depicted the negative things classmates, non-Ghanaian language teachers and parents say and do towards the study of Ghanaian language at the SHS:

sometimes some teachers who do not teach Fante say that when we study Fante we will not get job to do and that when we study Fante it means you do not know and understand English. ( $2^{\text {nd }}$ Year Student)

A third year student also affirmed this when he said

sometimes some teachers say that learning Fante is not beneficial because when we travel to another country and they do not speak Fante it will be difficult to communicate with them. They will always say if we want to talk about subject, you are talking about Fante.

The last statement indicates that some non-Ghanaian language teachers do not regard Ghanaian language (Fante) as an academic subject which is likely to develop 
students' cognitive skills. They see it as not being academically demanding or challenging.

The study also found that the actions and behaviour of non-Ghanaian language teachers discourage students from the study of Ghanaian language, as expressed in the statement by a second year student:

sometimes when they (referring to non-Ghanaian language teachers) are teaching us Science or Mathematics and we say it is time for Fante, they will say what is Fante. They do not allow us to go to the Fante class on time but when we attend Science or Mathematics classes late because we were in Fante class, sometimes they punish us or talk harshly to us.

This was confirmed during the observation. It was observed during the data collection process that students ended Fante classes a bit earlier; sometimes about five minutes to time to attend other classes but came to Fante classes about five to ten minutes late. For the time the researcher was in the schools for observation, this phenomenon occurred. Ironically, students attended English and other subjects' classes on time. Sometimes, Fante students were not given access to some classrooms even when such classrooms were empty, as expressed in the response of a third year student of School 6:

When we are in other classrooms some teachers who do not teach Fante will come and sack us from the classroom. There was one time we went to have class in a Science classroom, and when we were waiting for our teacher a Science teacher came and sacked us when there was no Science class going on.

A Fante teacher interviewed confirmed this when she said,

What the students said is true. There was a time we did not have a classroom because of overcrowding so I had a meeting with the Assistant Headmaster (Academic) and was agreed that we can use a class assigned to Science but not used very often but anytime we went there for classes we were sacked and this did not stop even when the Assistant Headmaster intervened. Eventually, we had to abandon the class for a small one behind the Assembly Hall.

Another Fante teacher indicated,

We do not have a permanent classroom so when it's time for Fante, we go round looking for an empty classroom which sometimes takes most of our time. Finally, we have to use a summer hut which has now become our classroom. 
The negative attitude ascribed to the study and use of Ghanaian language has made administrators of our educational institutions to pay little or no attention to it in terms of providing the necessary logistic and human support. In addition, students are sometimes punished for speaking Fante in class. This statement from the data attests to this:

if in English classes you speak Fante, you are punished but the teachers sometimes spoke Fante on the school compound and even in class.

Mwinsheikhe (2009) confirms this in a study in Tanzanian Secondary School about the dilemma of using English/Kiswahili as medium of instruction, which found that teachers used punishment as a coping strategy to maximize the use of English by students.

It was also found that comments and actions from parents were negative towards the study of Ghanaian language. The data showed that some parents detest their children studying Fante because they think it is a language they already know and use in their daily communication. As a result, they provide materials for other subjects and do otherwise for Fante. The following statements from the data confirm this:

i. Our parents think we do not know anything that is why we are studying Fante.

ii. Sometimes our parents are reluctant to buy books and other materials relating to the study of Fante but they do so for subjects like English, Science and Mathematics.

iii. My mother tells me that Fante is my own language so why should I study it in school and moreover when I study I will not get job after school.

These statements about parents' negative attitudes towards their children studying L1 in school agree with earlier findings by Andoh-Kumi (1997) that parents are disappointed when they learn that their children are learning their L1 at school.

It was also noted from the study that school administrators portrayed negative attitude towards Ghanaian language study in Senior High School. There were signs 'planted' on school compounds which prohibited the speaking of Ghanaian language. A third year student said:

We are not allowed to speak Fante on the compound. We speak Fante only in the Fante classes because Fante is a "local" language but in our dormitories we speak our local languages and we feel fine when we do that.

The researcher observed the following signs on school compounds which indicate that students are not permitted to speak Fante: "SPEAK ENGLISH ONLY", "SPEAK ENGLISH", "SPEAKING GHANAIAN LANGUAGE IS PROHIBITED”, and "DO 
NOT SPEAK VERNACULAR". The irony is that teachers spoke vernacular on campus. Most students interviewed indicated that they were sometimes punished for speaking Ghanaian language. We observed a student kneeling in front of the staff common room because he had spoken Fante. This finding is corroborated by earlier work by Prah (2009) narrating the experience of a colleague, Adams Bodomo (a Ghanaian linguist based in Hong Kong University) for how he was punished several times for speaking Dagaare, his native language, at school.

The study also found that other students say things which are discouraging and soul dampening to those who study Ghanaian language. A second year student said,

Some of our classmates say that when we learn Fante we will not get a good job to do so we should learn English, Science and Mathematics or Business.

Another interviewee indicated,

Because we study Fante, some of our classmates and some teachers say we do not know anything and therefore do not respect us. They say we are roaming in the school for nothing and that we did not come to study anything and sometimes say we should go home and sleep. Sometimes they may say this jokingly but it affects our morale of studying Fante.

This finding corroborates earlier findings by Guerini (2008) and Bamgbose (1991) that teachers, lecturers and students looked down upon and classified students who study their L1as academically weak.

The data showed that Ghanaian language teachers were described as not being intelligent and therefore referred to as 'local teachers' because they teach the language of the locality and cannot teach in other areas of the country. They were also referred to as 'colo' (a derogatory term used to describe old fashioned people). It was also noted from the responses that teachers who teach Ghanaian languages were perceived as people who cannot teach other subjects apart from Ghanaian language and that they know only the culture of their people and therefore, they are limited in knowledge. The data also revealed that both Ghanaian language teachers and students were seen as people who do not to speak good English. The following statements attest to this:

i. Our teachers are referred to as 'colo' which means they teach old things about our people and also dress like old people unlike the science and mathematics teachers who are young.

ii. People think our teachers cannot teach subjects like English so they cannot speak English properly. These have made two of our teachers to stop teaching Ghanaian language and are now teaching English. 
iii. They think that once we teach Fante, we cannot teach other subjects like English and Social Studies; as a result they say we cannot speak English properly.

The last but one statement above agrees with Bamgbose's (1991) assertion that teachers of African languages often try to redeem their 'image' by making sure that they are able to teach some other subjects as well.

Again, as a result of the negative attitudes expressed towards the study of Ghanaian languages in the SHS, many acts are consciously or unconsciously perpetrated in the school which discourage students from being enthusiastic or proud of studying a Ghanaian language. Besides Ghanaian language students not being provided with good classrooms, they are also not provided with Ghanaian language textbooks in the school library like the other subjects. A first year Ghanaian language student interviewee said,

When you go to the library you find a lot of books in science, mathematics and English but there are no Fante textbooks and in our classroom there are no fans like in other classrooms.

The data also indicated that discussions on students' performance concentrated mostly on Science, Mathematics and English to the detriment of Fante and other subjects. A teacher from School 8 confirmed this when he said,

Sometimes, I become very sad because at Parent Teacher Association and staff meetings they think about how to improve performances in Science, Mathematics, and English but not in Ghanaian language.

The Ghanaian language units of the Department of Languages in most of the schools used in the study are poorly resourced. A Ghanaian language teacher from School 6 interviewed indicated, there are many teachers in other subject areas but few in Fante. Besides, most students involved in the study were of the opinion that the authorities of their schools sometimes discriminate against them. The discrimination according to the data spans from provision of classrooms, provision of vehicles for excursion to even in school elections. For example, a second year student from School 5 indicated,

The authorities provide vehicles for excursion for other subject areas like Mathematics, Social Studies, Science and English but when it is the turn of Fante students they will say the school bus is busy or engaged.

Another second year student from School 5 added, 
People will not vote for you for any school position because you are learning Fante [Ghanaian language].

He added,

Most teachers insult us for studying Fante; English teachers, most especially insult us that it is because we study Fante that we perform poorly in English.

In the study, it was also found that students studying Ghanaian language were perceived by their colleagues as people who cannot read big books, that is why they opted to study Fante. A third year student from School 2 remarked,

Our friends tell us that it is because we cannot read big books that is why we study Fante. Sometimes, our parents very often say that it is because we cannot learn other subjects and pass that is why we are learning Fante.

Besides, some parents are disappointed when they hear that their children are studying Fante. A second year student said,

My mother tells me that Fante is my own language so why should I study it in school and moreover when I study I will not get job after school. Sometime our parents very often say that it is because we cannot learn other subjects and pass that is why we are learning Fante; that we are afraid of studying subjects like mathematics, science and literature.

People see Ghanaian languages to be "uncivilized" and "backward" and therefore treat them with disrespect. People accuse students studying Ghanaian languages as being "uncivilized".

One other interesting finding from the study was that most Ghanaian language teachers do not want to pursue a graduate program in Ghanaian language. They rather preferred pursuing programs in Teaching English as a Second Language and other Education related graduate programs. When asked why they would not want to pursue post-graduate programs in the language, they indicated that they are tired of the stigma attached to the teaching of Ghanaian language. In the same way, majority of the Ghanaian language students used in the study indicated that they do not want to pursue the study of Ghanaian language in the university or teach Ghanaian language. The main reason attributed to this is that Ghanaian language teachers and students in the university are not respected. One issue that cropped up in the study was that the negative attitude towards the study of Ghanaian language in schools has affected enrolment of students offering Ghanaian languages as part of their program in the SHS. Out of the total of 18,577 students in the schools used in the study, only 2,158 
$(11.6 \%)$ study a Ghanaian language as part of their program. This is made up of 841 (4.5\%) boys and 1317 (7.1\%) girls. More female students offer Ghanaian languages as part of their program than males. There are $476(2.6 \%)$ females more than males. It was further found that more students in Category B schools offer Ghanaian languages than in Category A schools. It was discovered from the study that five 'Category A' (three males only and two females only) in the Central Region do not offer Ghanaian language as part of their academic programs. Though these schools were not part of the study, the researcher thinks it is an interesting phenomenon to talk about. These "Category A" schools are producing students (future leaders) to detest their indigenous languages and culture. They rather offer French as part of their academic program. One of such schools even offers Latin. Table 1 illustrates the enrolment situation in SHSs used in the study.

Research question 2: How are students studying L1 in the SHS coping with the negative attitudes of people towards the study of L1?

This section sought to find out how SHS students studying Ghanaian language are coping with the negative attitude of people towards them. It was realized from the study that the Ghanaian language students have devised strategies to enable them to cope with the negative sentiments expressed by people. A third year Fante student has this to say as a way of encouraging his friends:

When they say that we are studying Fante because we are not intelligent we should not struggle with them and be angry but we should have patience and explain to them to understand why we are studying Fante.

The data also showed that some students cope with the negative attitudes towards the study of Ghanaian language by indicating that they opted out of their intrinsic motivation to study Fante. This was succinctly expressed by a second year student. He said,

I am encouraged because I decided to do Fante and so I am determined to study and pass and even if no one encourages me, I encourage myself and this is what I most of the time tell my friends who are studying Fante.

He continued in Fante se obiara annhye wo dzen a, woara hye woho dzen (literally meaning "if nobody encourages you, you should encourage yourself") so we should never give up. 
Table 1: Ghanaian language enrolment in selected SHS

\begin{tabular}{|c|c|c|c|c|c|c|c|c|}
\hline \multirow{2}{*}{ SCHOOL } & \multirow[b]{2}{*}{$\begin{array}{l}\text { NATURE } \\
\text { OF } \\
\text { SCHOOL }\end{array}$} & \multirow[b]{2}{*}{ CATEGORY } & \multirow[b]{2}{*}{$\begin{array}{l}\text { TOTAL SCH. } \\
\text { ENROLMENT }\end{array}$} & \multicolumn{2}{|c|}{$\begin{array}{l}\text { GH. LANG } \\
\text { STUDENTS }\end{array}$} & \multirow[b]{2}{*}{ TOTAL } & \multirow[b]{2}{*}{$\begin{array}{l}\text { PERCENTAGE } \\
\text { GH. LANG } \\
\text { LEARNERS }\end{array}$} & \multirow[b]{2}{*}{$\begin{array}{l}\text { NO OF GH } \\
\text { LANGUAGE } \\
\text { TEACHERS }\end{array}$} \\
\hline & & & & BOYS & GIRLS & & & \\
\hline 1 & Mixed & B & 1485 & 310 & 272 & 582 & 39.2 & 3 \\
\hline 2 & Mixed & B & 1735 & 45 & 73 & 118 & 6.8 & 1 \\
\hline 3 & Mixed & B & 1720 & 109 & 193 & 302 & 17.6 & 3 \\
\hline 4 & Girls & A & 1995 & 0 & 54 & 54 & 2.7 & 2 \\
\hline 5 & Mixed & A & 2210 & 13 & 62 & 75 & 3.4 & 2 \\
\hline 6 & Mixed & A & 2058 & 68 & 98 & 166 & 8.1 & 2 \\
\hline 7 & Mixed & B & 1248 & 33 & 73 & 106 & 8.4 & 2 \\
\hline 8 & Girls & B & 1321 & 0 & 135 & 135 & 10.2 & 2 \\
\hline 9 & mixed & B & 1254 & 75 & 102 & 177 & $14-1$ & 2 \\
\hline 10 & Mixed & B & 1201 & 90 & 80 & 170 & 14.1 & 1 \\
\hline 11. & Mixed & A & 2350 & 98 & 175 & 273 & 11.6 & 3 \\
\hline TOTAL & & & 18577 & 841 & 1317 & 2158 & 11.6 & 22 \\
\hline
\end{tabular}


Others cope with the situation by studying hard to prove to people that Ghanaian language students are as intelligent as students of other subjects. A second year student said,

I have decided to study hard and pass my final examination to prove to people that if you study Fante, it does not mean you are stupid.

Another second year student indicated that she is coping with the situation because her performance in Core Mathematics and Science is better than those studying Mathematics and Science as elective subjects. Some of the respondents indicated in the interview that they cope with the situation by taking encouragement from their teachers, parents and other people who have made it to the top by studying Fante (Ghanaian language). The following statements from student respondents attest to this:

A first year Fante student said,

Sometimes we take encouragement from our teachers and when we hear that people like you (referring to the researchers) studied Fante we become happy and this makes us forget the negative things people say about studying Fante.

A third year Fante student pointed out in the interview that,

Sometimes we are encouraged by Ghanaian language teachers who come on teaching practice. We are also encouraged by what we hear on radio stations. Lastly we are encouraged when we hear that some professors did Fante or other Ghanaian languages in school.

A second year student who wanted to major in science but was offered General Arts with Ghanaian language option had this to say during the interview:

I cope with the situation by taking encouragement from my mother who studied Ghanaian language -Fante at the university and became the best teacher in her district.

Research Question 3: How can the negative attitudes of people towards the study of L1 in SHS be changed?

Negative attitude has been a major problem in indigenous language use and study in education in multilingual societies, especially in Ghana (Amissah et al. 2001; OwuEwie 2007, 2013; Prah 2009). The negative attitude toward Ghanaian language study and use in school should be a matter of concern to the Ghanaian populace or else the nation will produce graduates who cannot read or write their mother tongue. The 
respondents gave responses which encompass what teachers, parents, government, school administrators, students and the general populace can do to change the negative attitudes towards Ghanaian language study. They were of the opinion that these people have major roles to play in this endeavour. Their roles include educating the populace on the importance of studying the Ghanaian languages, provision of Ghanaian language materials, using Ghanaian languages at home and making Ghanaian language a core subject in the SHS. Teachers and students interviewed were of the opinion that the government of Ghana should launch an extensive campaign to educate people on the benefits of studying Ghanaian languages to salvage the sinking image of Ghanaian language study and use in our schools and the nation as a whole. They also suggested that a body should be set up to oversee the use of Ghanaian language in education. A teacher indicated,

Because of the negative attitudes people have towards the study of Ghanaian language in our schools, government should make it as its top priority to educate people on the need to appreciate our language and culture.

In the interview, a first year student noted that.

government should make arrangements and select people who understand the benefit of studying Ghanaian language/Fante to educate people on television and on radio and any public gatherings on the importance of studying Ghanaian language in school.

Another student added that people should go to schools and talk to teachers and students on the importance of studying Fante. He added everybody who wants to work in government business should make sure he or she has a pass in Ghanaian language at the SHS.

Some teachers were also of the view that the negative attitude towards the study of Ghanaian language in the SHS can be salvaged when Ghanaian language is made a core subject in the SHS and the Colleges of Education. Students studying General Arts with Ghanaian language option believe that they have a role to play to change the negative attitudes people have towards the study of Ghanaian language in general and its study in the SHS in particular. A student has this advice for his colleagues;

We should let students who are not studying Fante to know that there is an advantage in learning Fante because the Fante student can write and translate something from Fante to English and from English to Fante but the English and science or mathematics student cannot do that.

Another student added, 
We those studying Ghanaian language should show positive attitude towards the language we study so that others can copy from us. We should make others have positive attitude towards the study of Ghanaian language.

The study also identified that SHS authorities can play a major role to change the negative attitude towards the study of Ghanaian language by treating the subject like any other subject on the school's curriculum. Students and teachers interviewed were of the opinion that school authorities should avoid subject discrimination and provide materials and resources equally for all subjects. The idea that some subjects are more important than others and are therefore given more attention should give way to equal treatment of all subjects. The participants added that negative attitudes towards the study of Ghanaian language in the SHS can be improved when textbooks in the Ghanaian language are provided in the school library as is done in the case of science, mathematics, English and social studies. According to the students interviewed, school authorities should help fight against the perpetration of negative acts geared towards the study of Ghanaian language and stop any action which portrays Ghanaian language as an unwelcome subject in Senior High Schools in the country.

\section{Conclusion}

The study sought to find out the negative attitudes towards the study of Ghanaian language in the Senior High School (SHS). The study purposively selected eleven (11) SHS, eleven (11) Ghanaian language teachers and 110 students. The main data collection strategies used were interview and observation. The study found that parents, school authorities, other language teachers and students, and the general populace have negative attitudes towards Ghanaian language study in the SHS. The negative attitudes are exhibited in what they say and in their actions and behaviours. The negative attitudes portrayed by these people have had negative influence on enrolment in the study of Ghanaian languages and also affected the morale of both Ghanaian language teachers and students. The study also found that students cope with the negative attitudes towards them through self-motivation, encouragement from their teachers, parents and Ghanaian language interns from the universities, and professors of Ghanaian language. It was also identified in the study that the negative attitudes towards the study of Ghanaian languages in the SHS can be changed through concerted efforts all teachers and students, parents, school administrators, the government and the general populace. Such concerted efforts, according to the study includes educating people on the benefits of studying Ghanaian language, provision of materials, and making the study of Ghanaian language a core subject in the SHS. Lastly, it was suggested that school authorities should desist from any act that prohibits the speaking of Ghanaian language on school premises. 


\section{References}

Adegbija, E., 1994. Language attitudes in Sub-Saharan Africa: A sociolinguistic overview. Cleveland: Multilingual Matters.

Amissah, P., K. Andoh-Kumi, S. Asare-Amoah, A. Awedoba, F. Mensah, E. Wilmot and S. Miske, 2001. IEQ2/Ghana Final report: The implementation of Ghana's school language policy. America Institute for Research.

Andoh-Kumi, K., 1997). Language Education Policies in Ghana. Accra: CRiGLE

Bamgbose, A., 1991. Language and the Nation: The language question in Sub-Saharan Africa. Edinburgh: Edinburgh University Press for the International African Institute.

Baker, C., 1992. Attitudes and Language. Clevedon: Multilingual Matters.

Bartram, B., 2010. Attitudes to Language, insights from comparative education. London: Continuum.

Bohner, G. and M. Wanke, 2002. Attitudes and Attitude Change. Hove: Psychology Press.

Cooper, R. L. and J. A. Fishman, 1974. The study of language attitudes. International Journal of the Sociology of Language 3: 5-19.

Coronel-Molina, S. M., 2009. Definitions and critical literature review of language attitude, language choice and language shift: Samples of language attitude surveys. Bloomington: Indiana University.

Crystal, D., 1997. English as a Global Language (2 ${ }^{\text {nd }}$ ed.). Cambridge: Cambridge University Press.

Dyers, C., 1998.Xhosa students' attitudes towards Black South African languages at the University of Western Cape. South African Journal of African Languages 19.2: 73-82.

Eagly, A. H. and S. Chaiken, 1998. Attitudes structure and function. In D. T. Gilbert, S. T. Fisk and G. Lindsey (eds.) Handbook of Social Psychology (269-322). New York: McGowan-Hill.

Edu-Buandoh, D. F., 2006. Multilingualism in Ghana: An ethnographic study of college students at the University of Cape Coast. Unpublished doctoral dissertation. University of Iowa, Iowa, USA.

Edwards, J., 1994. Multilingualism. London: Routledge. 
Fafunwa, A. B., J. I. Macauley and, J. A. Sokoya Funso, (eds). 1989. Education in Mother Tongue: The Ife Primary Education Research Project. Ibadan: University Press Ltd.

Fasold, R., 1984. The Sociolinguistics of Society. Oxford: Basil Blackwell.

Ferguson, C. A. 1996. National attitudes toward language planning. In T. Huebner (ed) In Sociolinguistic Perspectives: Papers in society 1959-1994 (295-303). New York NY: Oxford University Press.

Fishbein, M. and I. Ajzen, 1975. Belief, Attitudes, Intentions and Behaviour: an introduction to theory and research.MA: Addison Wesley.

Gok, T. and I. Silay, 2010. The effects of problem solving strategies on students' achievement, attitude and motivation. Latin-American Journal of Physics Education 4.1: 721.

Guerini, F., 2008. Multilingualism and language attitudes in Ghana: A preliminary survey. ETHNOREMA Lingue, Popolie Culture 4.4: 1-27.

Heugh, K., 2000. The case against bilingual and multilingual education in South Africa. Occasional Papers nr. 6. Cape Town, PRAESA.

Kwofie, R. J., 2001. A pilot study of language attitudes among University of Cape Coast students. Unpublished long essay. University of Cape Coast, Cape Coast.

Lewis, E. G., 1981. Bilingualism and Bilingual Education. Oxford: Pergamon.

Massey, D. A., 1998. Variations in attitudes and motivation of adolescent learners of French as a second language. Canadian Modern Language Review 43.3.

Mparutsa, C., J. Thondhalana, and N. Crawhall, 1990. An initial investigation into language attitudes of Secondary School students in Zimbabwe. In R. K. Herbert (ed.), Language and Society in Africa: The theory and practice of sociolinguistics (235-245). Johannesburg: Witwatersrand University Press.

Mwinsheikhe, H. M., (2009). Spare no means: battling with the English/Kiswahili dilemma in Tanzanian secondary school classroom. In B. Brock-Utne and I. Skattum (eds.), Languages and Education in Africa: A comparative and transdisciplinary analysis (223-235). UK: Symposium Books.

Omoniyi, T., 2013. Indigenous language capital and development. International Journal of the Sociology of Language 225: 7-28.

Owu-Ewie, C., 2007. The language policy of education in Ghana: constraints and the way forward. Journal of the African Language Teachers Association 9.2: 1-40. 
Owu-Ewie, C. 2009. The language policy of education in Ghana and Linguistic Human Rights. Languages and Linguistics 24:53-68.

Owu-Ewie, C., 2013. The National Literacy Acceleration Program and the language policy of education in Ghana. International Journal of Basic Education (IJOBED) 1: 95-104.

Prah, K. K., 2009. Mother-tongue education in Africa for emancipation and development: Towards the intellectualisation of African languages. In B. Brock-Utne and I. Skattum (eds.), Languages and Education in Africa: A comparative and transdisciplinary analysis (83-104). UK: Symposium Books.

Richards, J. C., J. Platt and H. Platt, 1992. Dictionary of Language Teaching and Applied Linguistics. Essex: Longman.

Saracaloglu, A. S., 2010. The relationship between students' attitudes toward foreign language and foreign language achievement: Approaches to the study of language and literature. Paper presented at the $1^{\text {st }}$ International Conference on Language Attitude. Dokuz Eylul University, Buca.

Salta, K. and C. Tzougraki, 2004. Attitudes towards chemistry among $11^{\text {th }}$ grade students in High Schools in Greece. Science Education 88: 353-547.

Sarfo, E., 2012. Ghanaian university students' attitudes towards English. International Review of Social Sciences and Humanities 4.1: 86-99.

Saville-Troike, M., 1989. Attitudes towards Communicative Performance: The ethnography of communication. Oxford: Oxford University Press.

Siti, N. G. 2008. Learner background and their attitudes towards studying literature. Malaysian Journal of EFL Research 4: 1-17

Smit, U., 1996. A New English for a New South Africa? Language attitudes, language planning and education. Vienna: Braumuller.

Wamalwa, E. W., 2013. Multilingualism and language attitude: Students perceptions towards Kiswahili in Mtwara region of Tanzania. Research in Humanities and Social Sciences. Retrieved from iiste.org, 13/3/2014.

Webb, V. N., 1996. English and language planning in South Africa: The flip side. In V. De Klerk (ed.), Focus on South Africa. Amsterdam: John Benjamins. 


\section{Appendix}

\section{Interview Guide}

\section{a. Pupils' Interview Guide}

1. Have you wanted to study L1 in SHS?

2. If not, how did you feel when you were asked to study L1?

3. What is the attitude of people towards the study of Ghanaian language in the SHS?

4. What negative things do people say about you studying L1 at SHS? (Negative attitudes of parents, teachers, colleagues etc)

5. How do you feel studying L1?

6. What is your perception of teachers who teach Ghanaian language?

7. Will you want to pursue the study of Ghanaian Language in the university? Give reasons for your response)

8. Will you want to teach Ghanaian Language? (Give reasons for your response)

9. What things in the school discourage you from being enthusiastic/proud about studying L1

10. If you are given an option will you change your program because of the L1 component? If yes, why?

11. What can be done to change the negative attitudes towards L1 study?

12. What are you doing to cope with the negative attitudes expressed about you studying L1 at the SHS?

\section{b. Teachers' Interview Guide}

1. What is your major in college?

2. Teaching other subjects (Do you teach other subjects apart from Ghanaian language?)

3. Do you prefer to teach other subjects? If yes, why?

4. Motivation for teaching Ghanaian language (Do you have motivation for teaching indigenous language?)

5. Do you have motivation from colleagues who teach other subjects? 
6. Motivation to study Ghanaian language from students/parents/school authorities, colleagues

7. Attitude from students - enthusiasm, acquisition of language materials, punctuality to class etc.

8. Attitude of non-Ghanaian language teacher (What do non-indigenous language teachers say about the teaching of the language?)

9. Further studies in Ghanaian language (Would you want to pursue your graduate course in Ghanaian Language? If yes, why? If no, why?)

10. Change of attitude (How can we change the negative attitude towards the study of Ghanaian language? 